\title{
Assessing health status over time: impact of recall period and anchor question on the minimal clinically important difference of copd health status tools
}

H. J. Alma ${ }^{1,2^{*}}$ (D) C. de Jong ${ }^{1,2}$, D. Jelusic ${ }^{3}$, M. Wittmann ${ }^{3}$, M. Schuler ${ }^{4}$, B. J. Kollen ${ }^{1}$, R. Sanderman ${ }^{5,6}$, K. Schultz ${ }^{3}$, J. W. H. Kocks ${ }^{1,2}$ and T. Van der Molen ${ }^{1,2}$

\begin{abstract}
Background: The Minimal Clinically Important Difference (MCID) assesses what change on a measurement tool can be considered minimal clinically relevant. Although the recall period can influence questionnaire scores, it is unclear if it influences the MCID. This study is the first to examine longitudinally the impact of the recall period of an anchor question and its design on the MCID of COPD health status tools using the COPD Assessment Test (CAT), Clinical COPD Questionnaire (CCQ) and the St. George's Respiratory Questionnaire (SGRQ).

Methods: Moderate to very severe COPD patients without respiratory co-morbidities were recruited during 3-week Pulmonary Rehabilitation (PR). CAT, CCQ and SGRQ were completed at baseline, discharge, 3, 6, 9 and 12 months. A 15point Global Rating of Change scale (GRC) was completed at each follow-up. A five-point GRC was used as second anchor at 12 months. Mean change scores of a subset of patients indicating a minimal improvement on each of the anchor questions were considered the MCID. The MCID estimates over different time periods were compared with one another by evaluating the degree of overlap of Confidence Intervals (Cl) adjusted for dependency.
\end{abstract}

Results: In total 451 patients were included (57.9 \pm 6.6 years, 65\% male, 50/39/11\% GOLD II/III/IV), of which 309 completed follow-up. Baseline health status scores were 20.2 \pm 7.3 (CAT), $2.9 \pm 1.2$ (CCQ) and $50.7 \pm 17.3$ (SGRQ). MCID estimates for improvement ranged -3.1 to -1.4 for CAT, -0.6 to -0.3 for CCQ, and -10.3 to -7.6 for $S G R Q$. Absolute higher - though not significant - MCIDs were observed for CAT and CCQ directly after PR. Significantly absolute lower MCID estimates were observed for CAT (difference - 1.4: $\mathrm{Cl}-2.3$ to -0.5 ) and CCQ (difference - 0.2: Cl -0.3 to -0.1 ) using a five-point GRC.

Conclusions: The recall period of a 15-point anchor question seemed to have limited impact on the MCID for improvement of CAT, CCQ and SGRQ during PR; although a 3-week MCID estimate directly after PR might lead to absolute higher values. However, the design of the anchor question was likely to influence the MCID of CAT and CCQ.

Trial registration: RIMTCORE trial \#DRKS00004609 and \#12107 (Ethik-Kommission der Bayerischen Landesärztekammer).

Keywords: Chronic obstructive pulmonary disease (COPD), Health status, Clinical COPD questionnaire (CCQ), COPD assessment test (CAT), St. George's respiratory questionnaire (SGRQ), Minimal clinically important difference, Clinically relevant change, Global rating of change scale, Recall period, Pulmonary rehabilitation

\footnotetext{
* Correspondence: h.j.alma@umcg.nl

${ }^{1}$ University of Groningen, University Medical Center Groningen, Department

of General Practice and Elderly Care Medicine, HPC FA21, Postbox 196,

NL-9700, AD, Groningen, The Netherlands

${ }^{2}$ University of Groningen, University Medical Center Groningen, Groningen

Research Institute for Asthma and COPD (GRIAC), Groningen, The Netherlands

Full list of author information is available at the end of the article
}

(c) The Author(s). 2018 Open Access This article is distributed under the terms of the Creative Commons Attribution 4.0 International License (http://creativecommons.org/licenses/by/4.0/), which permits unrestricted use, distribution, and reproduction in any medium, provided you give appropriate credit to the original author(s) and the source, provide a link to the Creative Commons license, and indicate if changes were made. The Creative Commons Public Domain Dedication waiver (http://creativecommons.org/publicdomain/zero/1.0/) applies to the data made available in this article, unless otherwise stated. 


\section{Background}

Health status can be defined as "the impact of health on a person's ability to perform and derive fulfilment from the activities of daily life" [1]. Its measurement is a standardized means of quantifying this impact on a patient's daily life, health and wellbeing [1, 2]. Multiple general- and disease-specific health status tools have been developed to detect and quantify health status $[3,4]$. Physiological measures alone do not reflect the full impact of the disease and correlations with Health-Related Quality of Life (HRQoL) are often weak [4]. Determining treatment effects requires a parameter that assesses to what extent change on a health status tool can be considered clinically relevant. The Minimal Clinically Important Difference (MCID) is used to evaluate this. It has been defined as "the smallest difference in score, which patients perceive as beneficial and which would mandate a change in the patient's management" [5]. Observed change should exceed the estimated MCID value in order to be clinically relevant.

MCID estimates can be determined using both anchorand distribution-based methods [6-8]. A frequently applied anchor-based technique is the use of a reference (anchor) question, requiring patients to retrospectively assess their current health state compared to a prior measurement in time or their experienced degree of change over time [6-8]. This anchor question usually consists of multiple ordinal reply options varying from much worse, a little worse, no change, a little better up to much better $[9,10]$. The technique may also be referred to as patient-referencing [6]. In the literature, several descriptions are used for this kind of anchor question: Global Rating scale of Change (GRC), Patient Global Impression of Change, Global Perceived Change, Transition Rating Scale and many more $[9,10]$. The MCID of a health status instrument can be determined by calculating the mean change score observed for those patients indicating a minimal change (little better or little worse) on the anchor question, assuming data being normally distributed [9].

The use of these patient rating scales has pros and cons. Its main strengths are the ease of administration and MCID determination, as well as the involvement of a patient-related clinical anchor [9]. However, it remains unclear over which period of time change on a GRC should be assessed and how many answering options the anchor question should include. When assessing change over a longer period of time, it might be more difficult for the patient to recall their former health state. A longer recall period could result in a different MCID [10]. On the other hand, shorter periods of measurement may not reflect real change. There is no golden standard in defining an instrument's MCID [11].

In COPD much focus is nowadays on health status measurement $[12,13]$, because spirometry assessment has only a weak to moderate correlation with the patient's wellbeing [14, 15]. The COPD Assessment Test (CAT) [16], the Clinical COPD Questionnaire (CCQ) [17], and the St. George's Respiratory Questionnaire (SGRQ) [18] are recommended by the Global initiative for Chronic Obstructive Lung Disease (GOLD) for the assessment of COPD in order to determine whether a patient is symptomatic and to what extent therapy has been successful [19]. CAT and CCQ are most applicable in clinical practice, and SGRQ in scientific research $[19,20]$.

Various studies examined the MCID of the CCQ to be $0.40-0.50$ [21-26], including three studies using an anchor question with recall periods ranging from two to three days [21] up to three weeks [25] and eight weeks [23]. The MCID of the CAT was estimated to be two to three points [24-28], of which three studies used an anchor question with recall periods of three weeks [25] and eight weeks [27, 28]. For the SGRQ, the MCID of four points is frequently used in clinical trials. However, estimates in the literature range from four to eight points [25, 29-31], of which two studies used patient-referencing techniques with recall periods of three weeks [25] and sixteen weeks [29, 31]. No studies have investigated the influence of the recall period of the anchor question and the number of its ordinal reply categories upon the MCID of these instruments. Therefore, this study aimed to investigate the impact of the length of the anchor's recall period and the number of reply options on the GRC on the MCID of the most frequently used health status tools CAT, CCQ and SGRQ in patients with COPD recruited from a Pulmonary Rehabilitation (PR) setting.

\section{Patients and methods}

\section{Study subjects}

The Routine Inspiratory Muscle Training within COPD Rehabilitation (RIMTCORE) study was a real-life randomized controlled trial (trial number \#DRKS00004609) in the Klinik Bad Reichenhall, Center for Rehabilitation, Pulmonology and Orthopedics in Germany [32]. Patients were included between February 2013 and July 2014. Detailed inclusion- and exclusion criteria have been published elsewhere [25, 32]. This study is a secondary analysis of a subsample including COPD participants GOLD II-IV aged $\geq 18$ years, who gave informed consent, without respiratory co-morbidities (e.g. bronchiectasis, asthma, history of bronchial carcinoma, sarcoidosis, tuberculosis), or alpha-1-antitrypsin deficiency.

\section{Study design and data collection}

Patients participated in an intensive three-weeks full-day inpatient rehabilitation program tailored to the patient's individual needs including components of physical training, education, smoking cessation, physiotherapy and counselling $[25,32]$. Patient characteristics and post-bronchodilator spirometry were collected at baseline and after three weeks at the end of PR. Primary parameters collected for this sub-study were the CAT (no recall period), CCQ (weekly 
version) and SGRQ (monthly version) at baseline, discharge and during follow-up measurements at three, six, nine and twelve months. Measurements were taken in the clinic before and after PR. Patients were blinded to their previous answers during PR. The remaining follow-up questionnaires were sent to the patient's home by regular mail.

The CAT is an eight-item one-dimensional scale with item scores ranging from zero to five (zero: no impairment; five: maximum impairment), summing up to a total of maximum 40 points [16]. The CCQ consists of ten items scoring from zero to six (zero: no impairment; six: maximum impairment) [17]. Domain scores (symptoms, functional status and mental status) and the total questionnaire score can be determined by summing all relevant item scores divided by the number of items. The SGRQ has 50 items divided over the domains symptoms, activities and impact [18]. Scores are calculated using the developers' scoring file. Domain and total SGRQ scores can range from zero to 100 (zero: no impairment, 100: maximum impairment). Scores of CAT and CCQ were multiplied and standardized into a scale from zero to 100 to be comparable with SRGQ. All three questionnaires were validated and reliable in primary and secondary care, as well as PR for COPD patients $[18,29,33,34]$. The tools are recommended according to the GOLD guidelines [19].

At each follow-up moment a 15-point Likert scale GRC anchor question was scored by the patient requiring assessment of their global health in relation to COPD compared with the start of PR (see Additional file 1: Figure S1). Answers were marked on a scale from -7 to +7 , ranging from very much worse to very much better and zero equalling no change [9]. At 12-months follow-up a five-point GRC, analogue to the second question of the SF-36, was also scored by the patient (see Additional file 1: Figure S2) [35]. It required patients to rate their general health compared to one year prior. Patients could assess their status as the same, somewhat better or somewhat worse, or as much better or much worse. Both GRCs are frequently used in MCID research [9]. The term recall period in this sense, refers to the recall period of the GRCs.

\section{Determining the MCID}

Scores for CAT, CCQ and SGRQ refer to their total scores. All change scores on the three questionnaires were calculated as the difference between baseline and each respective follow-up measurement. Negative change on these health status tools indicated improvement and positive change represented deterioration in HRQoL. Changes on these instruments were categorized using the corresponding score on the GRC anchor question. Scores of 0 and \pm 1 on the 15 -point GRC indicated no change; scores of \pm 2 and \pm 3 represented a minimal change; scores of \pm 4 and \pm 5 were summarized as a moderate change; and scores of \pm 6 and \pm 7 indicated a large change [9]. The five-point GRC resulted in a division of patients as not changed, somewhat better, somewhat worse, much better, or much worse [35]. MCID estimates for the CAT, CCQ and SGRQ total scores were calculated as the mean change scores compared with baseline including the $95 \%$ Confidence Interval $(95 \% \mathrm{CI})$ of those patients indicating a minimal improvement $(+2$ and +3$)$ on the GRC at each follow-up measurement, after checking for normality of distribution of the data. In addition to the 15-point Likert GRC scale, the five-point anchor question was used in a similar way to classify patients as somewhat better. Only patients that indicated an improvement on the GRC were included, since patients tend to get better after intervention and a limited number of patients were expected to deteriorate.

\section{Data analysis}

Data analysis was performed using SPSS 23.0 (IBM, Chicago, USA). Descriptive data were evaluated at baseline for either frequencies with percentages (\%), mean with Standard Deviation (SD) or median with range. This was depending on the variable characteristics and/or normality of distribution. CAT, CCQ and SGRQ were evaluated at baseline (T0), at discharge (T1), after three months (T2), after six months (T3), after nine months (T4) and after twelve months (T5). Normality of distribution was assessed using histograms combined with skewness and kurtosis results. Values between -1 and +1 were considered indicative for normality. Mean and standard deviations (or median and range) were calculated for each measurement. Data were checked for floor- and ceiling effects defined as more than $15 \%$ of the patients in the lowest and highest $10 \%$ of the maximum scale score [36]. All health status change scores were calculated between baseline and each follow-up measurement. These change scores were tested for significance using paired t-tests after verifying normality of distribution. All tests were assessed for significance using the level $p<0.05$.

The MCID determination process included several steps. First, correlations between the GRC anchor questions, and the CAT, CCQ or SGRQ were assessed using Pearson or Spearman correlation coefficients depending on normality of distribution. Correlations needed to be $\geq 0.30$ (preferably $\geq 0.50$ ) to be eligible as anchor [7]. Next, participants were categorized according to their GRC score at each follow-up measurement. The respective change versus baseline was tested for significance using paired t-tests after checking for normality. Each MCID estimate was calculated as the mean change score compared with baseline including its $95 \% \mathrm{CI}$ for those patients indicating a minimal improvement/somewhat better on the GRC for each follow-up moment. Correspondence between the 15-point and five-point GRC was analysed using cross tabulations, correlation coefficients and bar charts. 
All MCID estimates were tested for significance with one another by determining the degree of overlap of the adjusted CIs. Due to the dependency of the data, the Intra Class Correlation Coefficient (ICC) between follow-up measurement and baseline was calculated and used to construct CIs. Adjusted CIs were calculated based on the ICC between follow-up moment and baseline [37]. The degree of dependency affects the width of the CI required to be able to test for significant differences between the various MCID estimates. Results were visualized in plots. A lack of overlap between the MCID estimates and their respective $\mathrm{CI}$ indicated significant differences between MCIDs. Finally, the MCID estimates and their adjusted CIs from the current study were also compared with the available thresholds from the literature (CAT 2.00, CCQ 0.40, and SGRQ 4.00 points).

\section{Results}

\section{Patient characteristics}

This secondary analysis of the RIMTCORE trial included 451 patients [32]. All patients had completed baseline data and at discharge, with the exception for one incomplete CCQ questionnaire, two incomplete CAT questionnaires and four incomplete SGRQ questionnaires at discharge. During follow-up 355 patients had completed data after three months; 319 after six months; 304 after nine months; and 309 after twelve months (Fig. 1). In total, eight patients died during follow-up according to our knowledge, 41 dropped out at own request and a varying number of non-responses at follow-up was present. Mean age was 58 years, $65 \%$ was male and had a mean Forced Expiratory Volume in $1 \mathrm{~s} \%$ predicted (FEV1\%pred) of $50.4 \pm 15.1$ (Table 1). There were no significant baseline differences between patients completing the 12-months follow-up and those who did not. Full patient characteristics at baseline have been published elsewhere [25].

\section{Health status scores}

CAT, CCQ and SGRQ total scores were normally distributed for all measurement moments between T0 and T5. Completed pairs of change scores (follow-up vs. baseline) were included only (pair-wise deletion). There were no floor- and ceiling effects observed. There were no significant baseline differences in health status between complete and incomplete follow-up patients (Table 1). Mean baseline scores were $20.2 \pm 7.3$ (CAT), $2.9 \pm 1.2$ (CCQ) and $50.7 \pm 17.3$ (SGRQ) (Table 1). Mean change after twelve months follow-up was significant compared with baseline of -0.9 (95\% CI -1.7 to -0.1) for CAT; -0.2 (95\% CI -0.3 to -0.1) for CCQ; and -3.9 (95\% CI -5.7 to -2.2 ) for SGRQ (Table 2).

\section{Minimal clinically important differences for CAT, CCQ and SGRQ}

All change scores and 15-point anchor question scores were normally distributed. The five-point GRC at 12 months was treated as non-parametric data. At T1, one patient had a missing GRC score. No other GRC scores were missing for T2-T5. Correlations between the five-/15-point anchor questions and the health status change scores on the CAT, CCQ and SGRQ were all $\geq 0.30$, except for CCQ and CAT at T1 (Table 3). The Spearman correlation coefficient between the five- and 15-point GRC at 12 months was 0.81.The overlap between the five-point GRC and 15-point GRC classification at 12 -months was $55 \%$ based upon a cross-tabulation (Fig. 2).

A subset of the total patient population, indicated a minimal improvement according to their GRC score. Patients indicating a minimal improvement on the 15-point GRC (scores of +2 or +3 ) noted significant absolute mean changes between the start of pulmonary rehabilitation and twelve months follow-up measurement of -2.8 (95\% CI -4.2 to -1.4$)$ on the CAT; -0.5 ( $95 \% \mathrm{CI}-0.7$ to -0.3$)$ on the CCQ; and -8.8 (95\% CI -11.8 to -5.8 ) on the SGRQ (Table 4). MCID estimates ranged from -3.1 to -2.3 for CAT; -0.6 to -0.4 for CCQ; and from -10.3 to -7.6 for the SGRQ. Mean change scores of those patients feeling somewhat better on the five-point GRC after 12 months were -1.4 for CAT (95\% CI -2.7 to -0.1$),-0.3$ for CCQ (95\% CI -0.5 to -0.2 ), and -7.7 for SGRQ (95\% CI -10.5 to - 4.8) (Table 4).

\section{Tests of significance between MCID estimates}

ICC values ranged $0.5-0.7$ for CAT, 0.5-0.7 for CCQ, and 0.6-0.7 for SGRQ (Table 5).

Figures 3 and 4 visually plot the MCID estimates for CAT, CCQ and SGRQ including their respective adjusted confidence intervals for each recall period on both GRCs. Overlap was present for all CAT MCID estimates, except for the twelve months estimate using the five-point anchor question compared with the 15-point GRC. A significantly absolute lower MCID estimate was observed for CAT using the 5-point GRC (difference -1.4: adjusted CI -2.3 to -0.5$)$. The MCID measured with the 15-point GRC over the nine months period as well as the MCID using the five-point anchor question overlapped with the CAT estimate from the literature of two points.

The MCID plotted for the CCQ visualized that all estimates with their corresponding CIs overlapped one another, except for the twelve months estimate with the five-point GRC compared with the 15-point GRC (Fig. 3). A significantly absolute lower MCID estimate was observed for CCQ using the 5-point GRC at 12 months (difference - 0.2: CI -0.3 to -0.1 ). All estimates included the MCID from the literature of 0.40 points, except for the three weeks 15-point GRC anchor question estimate.

The plot for the MCID of the SGRQ showed all ranges overlapping one another, except for the nine months 15-point GRC anchor question method, which was significantly different from the three weeks 15-point GRC estimate 


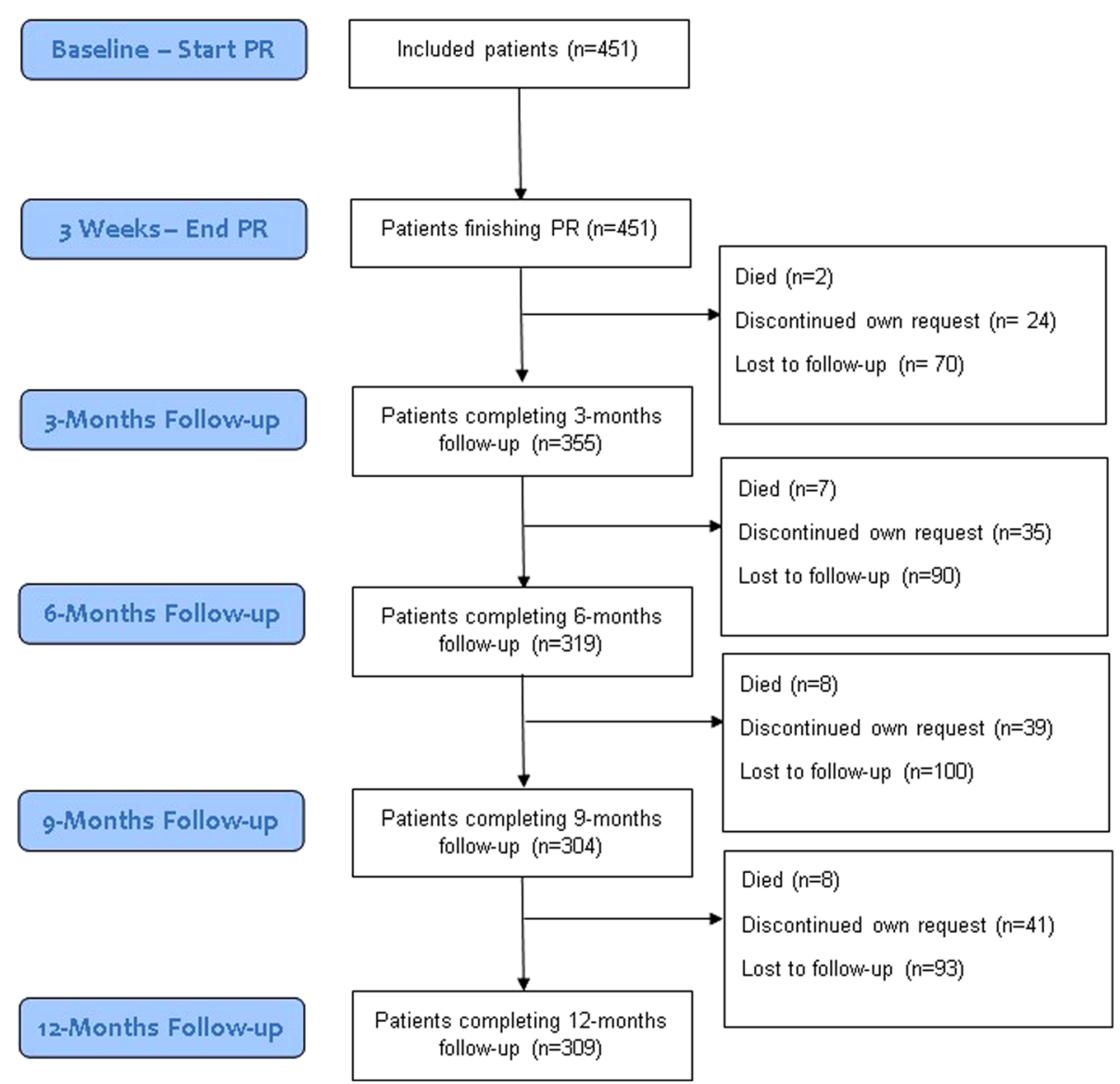

Fig. 1 Consort flow-chart of the number of patients during follow-up

Table 1 Baseline patient characteristics

\begin{tabular}{|c|c|c|c|c|}
\hline & $\begin{array}{l}\text { Baseline all patients } \\
N=451\end{array}$ & $\begin{array}{l}\text { Patients with complete follow-up } \\
N=309\end{array}$ & $\begin{array}{l}\text { Patients with incomplete follow-up } \\
N=142\end{array}$ & Significance testing \\
\hline Age (years) ${ }^{a}$ & $57.9 \pm 6.6$ & $58.1 \pm 6.5$ & $57.5 \pm 6.6$ & $p=0.39$ \\
\hline Gender (male) $)^{b}$ & 65.0 & 63.8 & 67.6 & $p=0.43$ \\
\hline $\mathrm{FEV}_{1} \%$ pred $^{\mathrm{a}}$ & $50.4 \pm 15.1$ & $50.6 \pm 14.9$ & $50.0 \pm 15.6$ & $p=0.72$ \\
\hline GOLD $\|^{b}$ & $227(50.3)$ & $158(51.1)$ & $69(48.6)$ & \\
\hline GOLD \|\|$^{b}$ & $176(39.0)$ & $121(39.2)$ & $55(38.7)$ & $p=0.63$ \\
\hline GOLD IV & $48(10.6)$ & $30(9.7)$ & $18(12.7)$ & \\
\hline Smoking pack years ${ }^{a}$ & $42.6 \pm 23.5$ & $41.1 \pm 23.1$ & $45.9 \pm 24.0$ & $p=0.05$ \\
\hline $\mathrm{CAT}^{\mathrm{a}}$ & $20.2 \pm 7.3$ & $20.0 \pm 7.6$ & $20.8 \pm 6.8$ & $p=0.28$ \\
\hline CCQ Total ${ }^{\mathrm{a}}$ & $2.9 \pm 1.2$ & $2.8 \pm 1.2$ & $3.0 \pm 1.1$ & $p=0.06$ \\
\hline SGRQ Total ${ }^{a}$ & $50.7 \pm 17.3$ & $49.6 \pm 17.8$ & $53.0 \pm 16.2$ & $p=0.05$ \\
\hline
\end{tabular}

CAT COPD Assessment Test, CCQ Clinical COPD Questionnaire, FEV1\%pred Forced Expiratory Volume in 1 Second \% predicted, GOLD Global initiative for Chronic Obstructive Lung Disease, $N$ Number of Patients, SGRQ St. George's Respiratory Questionnaire

${ }^{\text {a }}$ Data expressed as mean \pm SD

${ }^{b}$ Data expressed as frequencies (\% of total)

Significance tested with independent t-tests or Chi Square tests at level $p<0.05$ 
Table 2 Health status baseline and change scores

\begin{tabular}{|c|c|c|c|c|c|c|}
\hline & $\mathrm{N}$ & CAT & CAT Standardized & CCQ Total & CCQ Total Standardized & SGRQ Total \\
\hline Change at discharge (T1) & 451 & $\begin{array}{l}-3.1^{*} \\
(-3.6 \text { to }-2.6)\end{array}$ & $\begin{array}{l}-7.8^{*} \\
(-9.1 \text { to }-6.5)\end{array}$ & $\begin{array}{l}-0.6^{*} \\
(-0.7 \text { to }-0.5)\end{array}$ & $\begin{array}{l}-9.7^{*} \\
(-11.2 \text { to }-8.3)\end{array}$ & $\begin{array}{l}-9.0^{*} \\
(-10.2 \text { to }-7.9)\end{array}$ \\
\hline Change after 3 months (T2) & 355 & $\begin{array}{l}-1.4^{*} \\
(-2.2 \text { to }-0.7)\end{array}$ & $\begin{array}{l}-3.6^{*} \\
(-5.4 \text { to }-1.8)\end{array}$ & $\begin{array}{l}-0.3^{*} \\
(-0.4 \text { to }-0.2)\end{array}$ & $\begin{array}{l}-4.3^{*} \\
(-6.2 \text { to }-2.5)\end{array}$ & $\begin{array}{l}-5.4^{*} \\
(-6.9 \text { to }-3.8)\end{array}$ \\
\hline Change after 6 months (T3) & 319 & $\begin{array}{l}-0.9^{*} \\
(-1.7 \text { to }-0.1)\end{array}$ & $\begin{array}{l}-2.3^{*} \\
(-4.2 \text { to }-0.4)\end{array}$ & $\begin{array}{l}-0.1 \\
\text { (- } 0.2 \text { to zero) }\end{array}$ & $\begin{array}{l}-1.8 \\
(-3.8 \text { to }+0.2)\end{array}$ & $\begin{array}{l}-4.9^{*} \\
(-6.5 \text { to }-3.2)\end{array}$ \\
\hline Change after 9 months (T4) & 304 & $\begin{array}{l}-1.1^{*} \\
(-1.9 \text { to }-0.4)\end{array}$ & $\begin{array}{l}-2.9^{*} \\
(-4.8 \text { to }-0.9)\end{array}$ & $\begin{array}{l}-0.2^{*} \\
(-0.4 \text { to }-0.1)\end{array}$ & $\begin{array}{l}-3.8^{*} \\
(-5.8 \text { to }-1.8)\end{array}$ & $\begin{array}{l}-5.2^{*} \\
(-6.9 \text { to }-3.4)\end{array}$ \\
\hline Change after 12 months (T5) & 309 & $\begin{array}{l}-0.9^{*} \\
(-1.7 \text { to }-0.1)\end{array}$ & $\begin{array}{l}-2.2^{*} \\
(-4.2 \text { to }-0.3)\end{array}$ & $\begin{array}{l}-0.2^{*} \\
(-0.3 \text { to }-0.1)\end{array}$ & $\begin{array}{l}-2.7^{*} \\
(-4.7 \text { to }-0.7)\end{array}$ & $\begin{array}{l}-3.9^{*} \\
(-5.7 \text { to }-2.2)\end{array}$ \\
\hline
\end{tabular}

Change scores reported as mean $(95 \% \mathrm{Cl})$. Change scores were calculated in comparison to baseline. Negative values represent improvement for CAT, CCQ and SGRQ. CAT and CCQ were standardized into a scale from zero to 100 to be comparable with SGRQ

95\% CI 95\% Confidence Interval, CAT COPD Assessment Test, CCQ Clinical COPD Questionnaire, N Number of patients, SGRQ St. George's Respiratory

Questionnaire, T1 Measurement at discharge, T2 3 months follow-up, T3 6 months follow-up, T4 9 months follow-up, T5 12 months follow-up

*Significance of change scores $p<0.05$ at $\mathrm{T} 1 / \mathrm{T} 2 / \mathrm{T} 3 / \mathrm{T} 4 / \mathrm{T} 5$ compared to baseline (T0)

and three months 15-point GRC estimate (Fig. 4). There were no significant differences between the five-point and 15-point GRC at 12 months. All estimates were significantly different from the four points estimate in the literature.

\section{Discussion}

\section{Summary of main findings}

This study found no systematic significant differences between various recall periods of a 15-point anchor question on the MCID for improvement of the COPD health status tools CAT, CCQ and SGRQ in a PR setting. Using this 15-point GRC, MCID estimates for improvement ranged 3.1 to -2.3 for CAT; -0.6 to -0.4 for CCQ; and -10.3 to - 7.6 for SGRQ. Higher absolute MCID estimates were observed for CAT and CCQ with a shorter three weeks recall period directly after PR, although not significant. The nine months recall period on the 15-point GRC for the SGRQ was significantly higher in absolute value when comparing with the estimates at three weeks and three months. However, an anchor question with only five answering options did result in significantly absolute lower MCIDs for CAT and CCQ in comparison with the 15-point GRC at 12 months. Estimates were - 1.4 for CAT (significant difference - 1.4), -0.3 for CCQ (significant difference - 0.2), and -7.7 for the SGRQ (non-significant difference - 1.1).

\section{Interpretation of findings}

The MCID ranges found in the current study for both CAT and CCQ were in correspondence with those available in the literature [21-28]. Recall periods on the anchor question of two to three days, three weeks and eight weeks have been used before for CAT and CCQ $[21,23,25,27,28]$. Most MCID estimates for the CAT in the current study were significantly higher than the two points threshold, which had been advocated using a five point GRC scale [27, 28]. Since CAT only allows for integer scores, a cut-off MCID of three points would be suggested here. For the CCQ, all recall periods and anchor question types included the 0.40 points MCID as reported in the literature, although our estimates were closer to 0.50 points [21-26]. Both five-point and 15-point GRCs were used generating a 0.40 MCID estimate for the CCQ [21, 23]. The estimates for the SGRQ in the current study were significantly higher compared with the existing four points MCID, which is used extensively in scientific research $[29,31]$. This MCID was among others based upon a five-point question requiring COPD patients to assess the treatment effects over a 16-week period. It did not require patients to assess their experienced change in health status, hence may result in a different MCID. The current study provided additional support to the recommendation by Welling et

Table 3 Correlations between health status change scores and the Global Rating of Change anchor questions

\begin{tabular}{lllllll}
\hline & 15-point GRC T1 & 15-point GRC T2 & 15-point GRC T3 & 15-point GRC T4 & 15-point GRC T5 & Five-point GRC T5 \\
\hline N of Patients & 451 & 355 & 319 & 304 & 309 & 309 \\
CAT change score & -0.23 & -0.33 & -0.40 & -0.43 & -0.41 & 0.46 \\
CCQ total change score & -0.29 & -0.42 & -0.44 & -0.48 & -0.47 & $\mathbf{0 . 5 0}$ \\
SGRQ total change score & -0.30 & -0.48 & $-\mathbf{0 . 5 1}$ & $\mathbf{- 0 . 5 8}$ & $\mathbf{- 0 . 5 4}$ & $\mathbf{0 . 5 7}$
\end{tabular}

Data reported as Pearson or Spearman correlation coefficients between the health status change scores and the anchor questions. Correlations $\geq 0.50$ are highlighted bold

CAT COPD Assessment Test, CCQ Clinical COPD Questionnaire, GRC Global Rating of Change scale, SGRQ St. George's Respiratory Questionnaire, T1 Measurement at discharge, T2 3 months follow-up, T3 6 months follow-up, T4 9 months follow-up, T5 12 months follow-up 


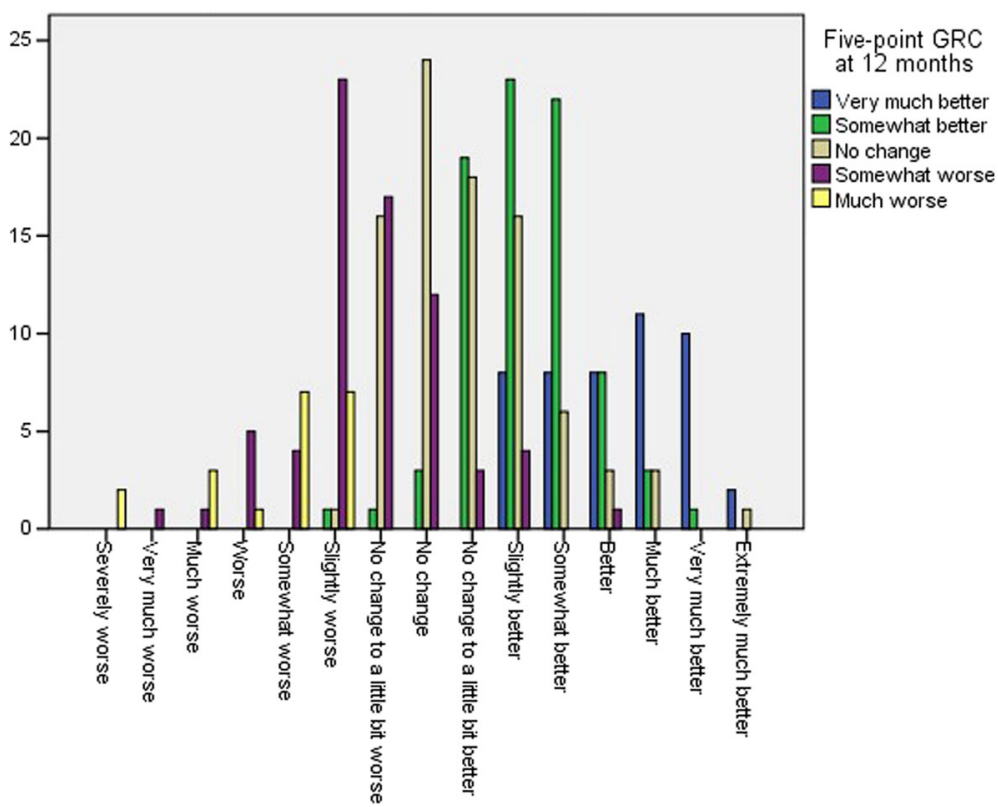

Fig. 2 Correspondence between the five- and 15-point Global Rating of Change scale at 12 months follow-up

al. [30] and Alma et al. [25] that the MCID of the SGRQ of four points should be set higher.

There was a remarkable significant difference between the five-point and 15-point anchor question scale in estimating the MCIDs for CAT and CCQ at 12 months, although the Spearman correlation between both anchor scales was strong. However, the classification of patients according to both GRCs was only for 55\% consistent, resulting thus in a different categorization of the degree of change assessed by patients themselves. Although the 15-point GRC was analysed as a seven-point scale, the patients had 15 answering options to choose from, compared with five on the other GRC. Too few reply options on an anchor question might lead to loss of relevant information, leading to less discriminative power and lower sensitivity [9]. It may result into lower MCIDs. This seems to be the case for the current study for both CAT and CCQ, and to a lesser extent for SGRQ as well. Earlier studies used only five-point GRCs for CAT and SGRQ [27-29, 31]. These studies showed lower absolute MCIDs. A five-point anchor

Table 4 MCID estimates for minimally improved patients as indicated on the GRC during follow-up

\begin{tabular}{|c|c|c|c|c|c|c|}
\hline Measurement period & $\mathrm{N}$ & CAT & CAT Standardized & CCQ Total & CCQ Total Standardized & SGRQ Total \\
\hline 15-point GRC T1-T0 & 196 & $\begin{array}{l}-3.1^{*} \pm 5.3 \\
(-3.9 \text { to }-2.4)\end{array}$ & $\begin{array}{l}-7.8^{*} \pm 13.2 \\
(-9.7 \text { to }-5.9)\end{array}$ & $\begin{array}{l}-0.6^{*} \pm 0.8 \\
(-0.7 \text { to }-0.4)\end{array}$ & $\begin{array}{l}-9.3^{*} \pm 14.0 \\
(-11.3 \text { to }-7.3)\end{array}$ & $\begin{array}{l}-8.4^{*} \pm 11.8 \\
(-10.1 \text { to }-6.7)\end{array}$ \\
\hline 15-point GRC T2-T0 & 107 & $\begin{array}{l}-2.7^{*} \pm 6.4 \\
(-4.0 \text { to }-1.5)\end{array}$ & $\begin{array}{l}-6.9^{*} \pm 16.1 \\
(-9.9 \text { to }-3.8)\end{array}$ & $\begin{array}{l}-0.4^{*} \pm 1.0 \\
(-0.6 \text { to }-0.2)\end{array}$ & $\begin{array}{l}-7.3^{*} \pm 16.8 \\
(-10.5 \text { to }-4.0)\end{array}$ & $\begin{array}{l}-7.6^{*} \pm 13.8 \\
(-10.2 \text { to }-4.9\end{array}$ \\
\hline 15-point GRC T3-T0 & 96 & $\begin{array}{l}-2.7^{*} \pm 6.7 \\
(-4.1 \text { to }-1.4)\end{array}$ & $\begin{array}{l}-6.8^{*} \pm 16.7 \\
(-10.2 \text { to }-3.5)\end{array}$ & $\begin{array}{l}-0.4^{*} \pm 1.1 \\
(-0.6 \text { to }-0.2)\end{array}$ & $\begin{array}{l}-7.0^{*} \pm 18.0 \\
(-10.6 \text { to }-3.3)\end{array}$ & $\begin{array}{l}-9.2^{*} \pm 14.0 \\
(-12.1 \text { to }-6.3\end{array}$ \\
\hline 15-point GRC T4-T0 & 80 & $\begin{array}{l}-2.3^{*} \pm 6.1 \\
(-3.7 \text { to }-1.0)\end{array}$ & $\begin{array}{l}-5.8^{*} \pm 15.2 \\
(-9.2 \text { to }-2.4)\end{array}$ & $\begin{array}{l}-0.5^{*} \pm 0.8 \\
(-0.7 \text { to }-0.3)\end{array}$ & $\begin{array}{l}-7.6^{*} \pm 13.8 \\
(-10.8 \text { to }-4.7)\end{array}$ & $\begin{array}{l}-10.3^{*} \pm 12.9 \\
(-13.2 \text { to }-7.4\end{array}$ \\
\hline 15-point GRC T5-T0 & 88 & $\begin{array}{l}-2.8^{*} \pm 6.7 \\
(-4.2 \text { to }-1.4)\end{array}$ & $\begin{array}{l}-7.0^{*} \pm 16.7 \\
(-10.5 \text { to }-3.5)\end{array}$ & $\begin{array}{l}-0.5^{*} \pm 1.0 \\
(-0.7 \text { to }-0.3)\end{array}$ & $\begin{array}{l}-8.3^{*} \pm 16.3 \\
(-11.7 \text { to }-4.8)\end{array}$ & $\begin{array}{l}-8.8^{*} \pm 14.1 \\
(-11.8 \text { to }-5.8\end{array}$ \\
\hline Five-point GRC T5-T0 & 81 & $\begin{array}{l}-1.4^{*} \pm 5.9 \\
(-2.7 \text { to }-0.1)\end{array}$ & $\begin{array}{l}-3.5^{*} \pm 14.7 \\
(-6.7 \text { to }-0.3)\end{array}$ & $\begin{array}{l}-0.3^{*} \pm 0.8 \\
(-0.5 \text { to }-0.2)\end{array}$ & $\begin{array}{l}-5.5^{*} \pm 13.8 \\
(-8.7 \text { to }-2.5)\end{array}$ & $\begin{array}{l}-7.7^{*} \pm 12.9 \\
(-10.5 \text { to }-4.8\end{array}$ \\
\hline
\end{tabular}

Minimal change scores reported as mean \pm SD $(95 \% \mathrm{Cl})$. Change is measured compared to baseline. Negative values represent improvement for CAT, CCQ and SGRQ. CAT and CCQ were standardized into a scale from zero to 100 to be comparable with SGRQ

* Significance of change scores $p<0.05$ at $\mathrm{T} 1 / \mathrm{T} 2 / \mathrm{T} 3 / \mathrm{T} 4 / \mathrm{T} 5$ compared to baseline (T0)

95\%Cl 95\% Confidence Interval, CAT COPD Assessment Test, CCQ Clinical COPD Questionnaire, GRC Global Rating of Change scale, $N$ number of patients, SD Standard Deviation, SGRQ St. George's Respiratory Questionnaire, TO Measurement at baseline, T1 Measurement at discharge, T2 3 months follow-up, T3 6 months follow-up, T4 9 months follow-up, T5 12 months follow-up 
Table 5 Determination of appropriate Confidence Intervals $(\mathrm{Cl})$ testing for significantly different MCIDs between time points

\begin{tabular}{|c|c|c|c|c|c|c|}
\hline & $\begin{array}{l}\text { 15-point } \\
\text { GRC T0-T1 }\end{array}$ & $\begin{array}{l}\text { 15-point } \\
\text { GRC T0-T2 }\end{array}$ & $\begin{array}{l}\text { 15-point } \\
\text { GRC T0-T3 }\end{array}$ & $\begin{array}{l}\text { 15-point } \\
\text { GRC T0-T4 }\end{array}$ & $\begin{array}{l}\text { 15-point } \\
\text { GRC T0-T5 }\end{array}$ & $\begin{array}{l}\text { Five-point } \\
\text { GRC T0-T5 } \\
\end{array}$ \\
\hline \multicolumn{7}{|l|}{ CAT } \\
\hline Mean change & -3.1 & -2.7 & -2.7 & -2.3 & -2.8 & -1.4 \\
\hline SD of the change & 5.3 & 6.4 & 6.7 & 6.1 & 6.7 & 5.9 \\
\hline $\mathrm{N}$ of patients & 196 & 107 & 96 & 80 & 88 & 81 \\
\hline ICC & 0.7 & 0.6 & 0.5 & 0.6 & 0.5 & 0.6 \\
\hline Z score required & 0.62 & 0.98 & 0.98 & 0.98 & 0.98 & 0.98 \\
\hline Standard Error & 0.4 & 0.6 & 0.7 & 0.7 & 0.7 & 0.7 \\
\hline $\mathrm{Cl}$ & -3.4 to -2.9 & -3.4 to -2.1 & -3.4 to -2.1 & -3.0 to -1.6 & -3.5 to -2.1 & -2.0 to -0.8 \\
\hline $\begin{array}{l}\text { Standardized mean } \\
\text { change and } \mathrm{Cl}\end{array}$ & $\begin{array}{l}-7.8 \\
(-8.4 \text { to }-7.2)\end{array}$ & $\begin{array}{l}-6.9 \\
(-8.4 \text { to }-5.3)\end{array}$ & $\begin{array}{l}-6.8 \\
(-8.5 \text { to }-5.2)\end{array}$ & $\begin{array}{l}-5.8 \\
(-7.4 \text { to }-4.1)\end{array}$ & $\begin{array}{l}-7.0 \\
(-8.8 \text { to }-5.3)\end{array}$ & $\begin{array}{l}-3.5 \\
(-5.1 \text { to }-1.90)\end{array}$ \\
\hline \multicolumn{7}{|l|}{ CCQ Total } \\
\hline Mean change & -0.6 & -0.4 & -0.4 & -0.5 & -0.5 & -0.3 \\
\hline SD of the change & 0.8 & 1.0 & 1.1 & 0.8 & 1.0 & 0.8 \\
\hline $\mathrm{N}$ of patients & 196 & 107 & 96 & 80 & 88 & 81 \\
\hline ICC & 0.7 & 0.6 & 0.5 & 0.7 & 0.5 & 0.6 \\
\hline Z score required & 0.62 & 0.98 & 0.98 & 0.62 & 0.98 & 0.98 \\
\hline Standard Error & 0.1 & 0.1 & 0.1 & 0.1 & 0.1 & 0.1 \\
\hline $\mathrm{Cl}$ & -0.7 to -0.5 & -0.5 to -0.3 & -0.5 to -0.3 & -0.6 to -0.4 & -0.6 to -0.4 & -0.4 to 0.2 \\
\hline $\begin{array}{l}\text { Standardized mean } \\
\text { change and } \mathrm{Cl}\end{array}$ & $\begin{array}{l}-9.3 \\
(-10.0 \text { to }-8.7)\end{array}$ & $\begin{array}{l}-7.3 \\
(-9.0 \text { to }-5.7)\end{array}$ & $\begin{array}{l}-7.0 \\
(-8.8 \text { to }-5.2)\end{array}$ & $\begin{array}{l}-7.7 \\
(-8.7 \text { to }-6.7)\end{array}$ & $\begin{array}{l}-8.3 \\
(-10.0 \text { to }-6.7)\end{array}$ & $\begin{array}{l}-5.5 \\
(-7.0 \text { to }-4.0)\end{array}$ \\
\hline \multicolumn{7}{|l|}{ SGRQ Total } \\
\hline Mean change & -8.4 & -7.6 & -9.2 & -10.3 & -8.8 & -7.7 \\
\hline SD of the change & 11.8 & 13.8 & 14.0 & 12.9 & 14.1 & 12.9 \\
\hline $\mathrm{N}$ of patients & 196 & 107 & 96 & 80 & 88 & 81 \\
\hline ICC & 0.7 & 0.7 & 0.7 & 0.7 & 0.6 & 0.6 \\
\hline Z score required & 0.62 & 0.62 & 0.62 & 0.62 & 0.98 & 0.98 \\
\hline Standard Error & 0.8 & 1.3 & 1.4 & 1.4 & 1.5 & 1.4 \\
\hline $\mathrm{Cl}$ & -8.9 to -7.9 & -8.4 to -6.8 & -10.1 to -8.3 & -11.2 to -9.4 & -10.3 to -7.4 & -9.1 to -6.3 \\
\hline
\end{tabular}

CAT COPD Assessment Test, CCQ Clinical COPD Questionnaire, Cl Confidence Interval, GRC Global Rating of Change scale, ICC Intraclass Correlation Coefficient, $N$ Number of Patients, SD Standard Deviation, SGRQ St. George's Respiratory Questionnaire, T0 Measurement at baseline, T1 Measurement at discharge, T2 3 months follow-up, T3 6 months follow-up, T4 9 months follow-up, T5 12 months follow-up

scale may therefore not discriminate sufficiently. Kamper S.J et al. recommended to include seven to 11 reply options for optimal discrimination [9]. Another difference between the current five-point and 15-point GRC was that the first one was a verbal scale, while the latter one was a numeric scale. Possibly this has influenced the classification as words may result in a different perception in comparison to numbers.

Using an anchor question to determine an instrument's MCID is common practice [6-8]. Jaeschke et al. were the first to use this approach in determining the MCID of the Chronic Respiratory Questionnaire (CRQ) using a 15-point Likert scale GRC [5]. Since then many have adopted this method, but have also applied alternative versions to determine the MCID. The approach is easy to administer and the single best measure of the significance of change from the patient's perspective [911]. However, anchor questions rely on the patient's ability to recall their former health state [9-11]. Accurate recall is determined by factors such as forgetting, more recent (impactful) health events, and current mood state [11]. Global Rating of Change scales may therefore not provide an accurate reflection of the real experienced change due to these recall biases.

It has been speculated that longer recall periods would lead to less accurate estimates of change and even to different MCIDs [10, 38-42]. Evaluation of change turned out to be more correlated with the current health state and severity of experienced symptoms, rather than with the former (baseline) condition [9, 10, 41-48]. There are, however, also studies that did not find specific differences between recall periods [39, 49-51]. There is no single optimal recall period 


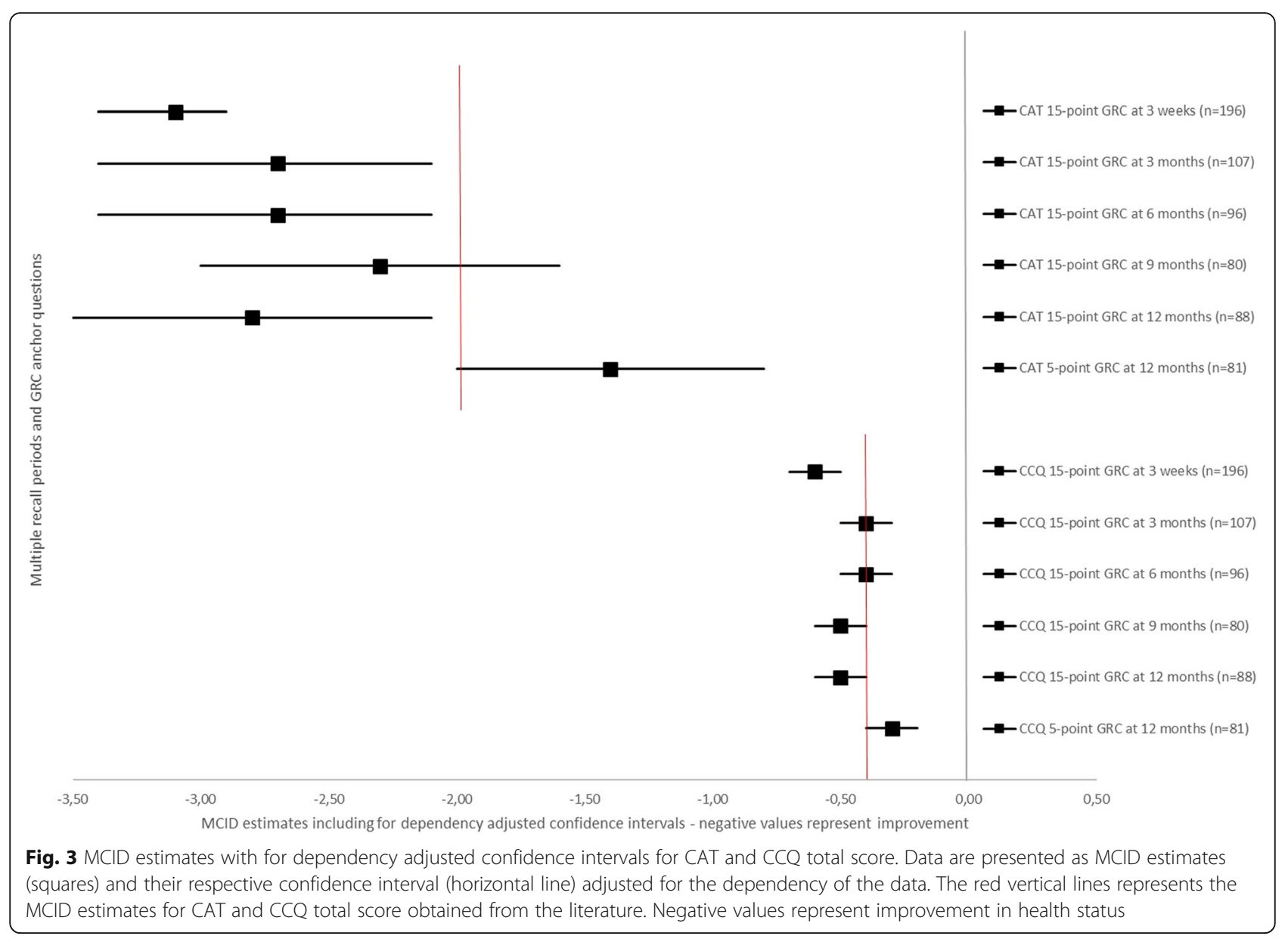

$[39,51]$. The required window is dependent upon whether or not acute effects need to be measured, whether acute events occur, as well as the nature of the disease $[39,52]$. Longer recall periods may therefore be appropriate for chronic conditions with slow changes. It was argued that the optimal length for measuring change on a PRO in COPD would be six to 12 months [53]. A recall period of more than one year could lead to problems due to the progressive nature of the disease. In addition to the impact of recall bias, a patient's evaluation of a specific health state might change over time due to a response shift [54]. This concept refers to a change in the meaning of the concept HRQoL for the patient. Response shift was demonstrated to have an influence on the MCID in HRQoL tools in breast cancer research [55]. Evidence for the influence of response shift as well as recall bias on the MCID of COPD health status is currently absent in the literature.

The current study had a fixed recall moment, which was related to the start of an intense PR program. The effects of PR would be expected to remain over a longer period of time, leading to less exacerbations and less acute changes in the health state of the COPD patients [56]. Jones et al. [53] recommended measurement of PROs in
COPD over a 6-12 months period as the optimal recall period, which our study did. The assessment of change compared with the start of PR, the expected stability of COPD symptoms over time after PR and the use of the optimal recall period might help explain why this study found stable MCID estimates during follow-up.

Correlations between the anchor question and the health status change scores were sufficient to be used as anchor, except for the three week measurement period. It may, therefore, not be surprising that those estimates were especially for CAT and CCQ higher than the other MCID estimates. Evaluating change directly after an impacting event, such as PR or exacerbations, could potentially bias the MCID measurement of an instrument. The estimates of the SGRQ seemed rather stable over time, perhaps because SGRQ is a more extensive and lengthier tool in comparison to the CAT and CCQ.

\section{Strengths and limitations}

This is the first study to investigate the impact of the recall period of the patient's GRC and its design on the MCID for improvement of COPD health status tools. It is to the best of our knowledge the only study, which 


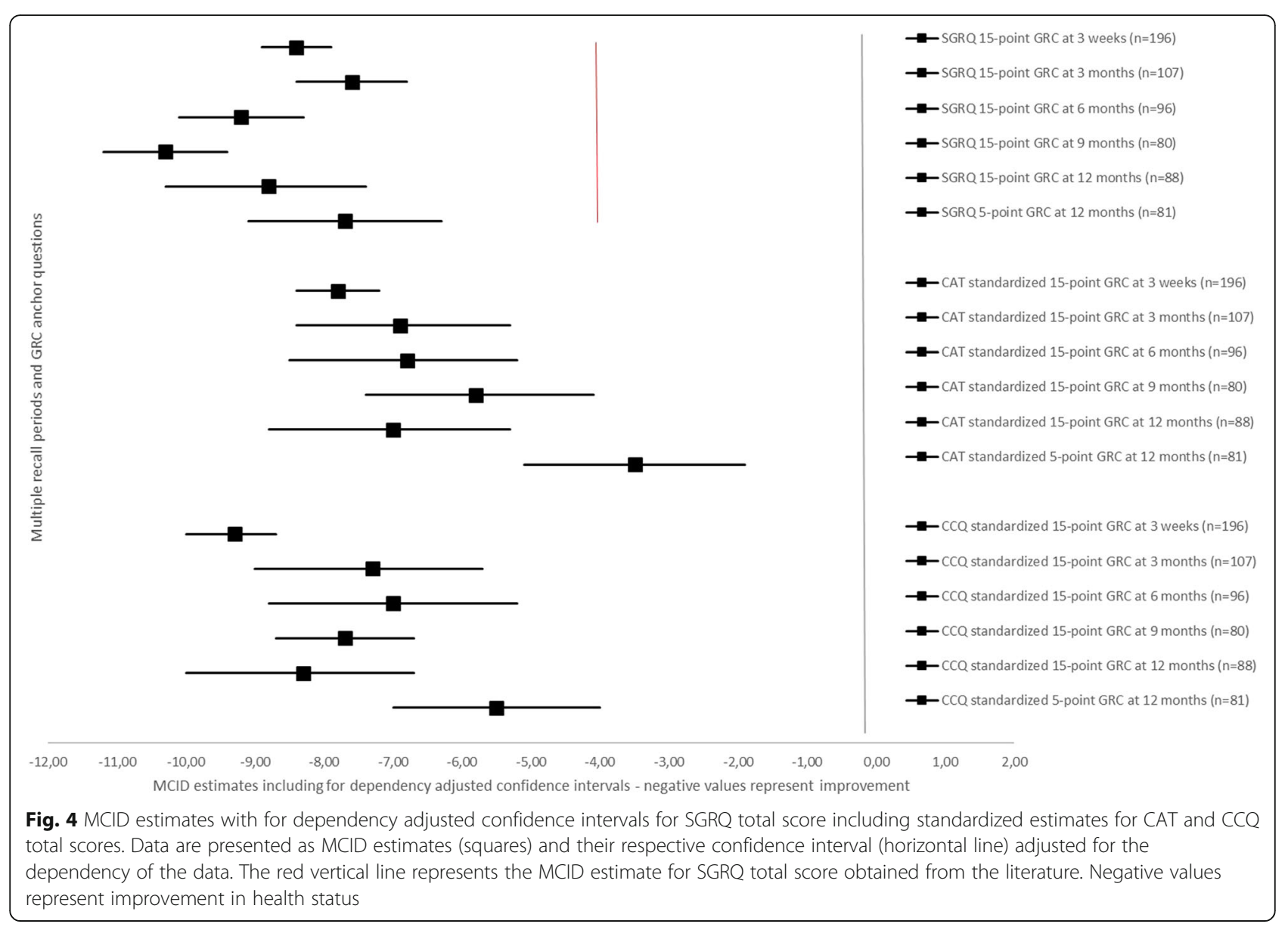

measured the MCID of CAT, CCQ and SGRQ in one study over multiple study periods, and included a unique test of significance for the MCID according to the methods of Afshartous et al. [37]. In the current study, MCIDs were tested over multiple periods of time. No correction for multiple testing was made, risking an increase in the probability to run a type I error. However, since this was a diagnostic study, we considered this to be of limited importance as there is no intention to make a formal statement about efficacy or safety based on hypothesis testing [57]. Furthermore, the confidence intervals for the MCID estimates were adjusted for the dependency of multiple follow-up data.

The results found in this study are valid for a PR setting. As MCIDs may differ per setting, the results need not necessarily be valid in other populations [11]. However, our results were in line with the existing MCIDs in the literature, which were also determined outside the field of PR. MCIDs were determined based upon a patient's perspective of their health status change. No clinician, neither the patient, was involved to make a judgement about the clinical relevance of the perceived change though. Correlations between the GRCs and the health status questionnaires were sufficient according to pre-determined criteria, however in fact these correlations are still only small to moderate.

Another limitation is that the data used in this study were based on improvement only, as the number of patients deteriorating for each follow-up period was small to allow for significance testing. MCIDs for improvement may, however, differ from those for deterioration [11]. Furthermore, this study determined the MCID over different recall periods using the 15-point GRC scale. The five-point anchor question was, however, only measured over a twelve month period. It would not be possible to conclude whether recall bias occurred for a five-point GRC. Last, the anchor-based MCID technique can be considered a population-based figure, rather than a reflection of the individual's change $[6-8,11]$. This is a limitation of the technique in itself. Using a larger sample would lead to regression to the mean of the MCID estimate, which is less subject to larger changes in an individual's health state.

\section{Implications for future clinical practice and theory}

No other evidence exists for the impact of the recall period and the design of the anchor question on the 
determination of MCIDs in COPD health status. Ideally, more research is needed to confirm or falsify the current findings in both a PR and other settings. It would be recommended to use multiple patient-referencing anchors over multiple periods of time to carefully estimate an instrument's MCID. Multiple MCIDs might potentially apply to practice for different time periods of measurement used in clinical trials. However, this study was the first to suggest otherwise. It indicated a differentiation might be needed between measurement of change directly after an impacting event and in stable patients, as this may be an important factor influencing recall bias.

\section{Conclusions}

Various recall periods on a 15-point anchor question seemed not to be associated with systematic significant differences in the MCIDs for improvement of the CAT, CCQ and SGRQ, with the exception of the shortest 3-week measurement period directly after PR for CAT and CCQ, which led to absolute higher MCID estimates. Measuring change with a shorter recall period directly after an impacting event might potentially bias measurement. Using an anchor question with less answering options over a one-year period of time in determining an instrument's MCID may also coincide with (significantly) lower absolute MCID estimates as less discriminative options might be available for the patient.

\section{Additional file}

Additional file 1: Figure S1. 15-point Global Rating of Change anchor question used at each follow-up moment. Figure S2. Five-point Global Rating of Change anchor question used at 12-months follow-up. (DOCX $163 \mathrm{~kb}$ )

\section{Abbreviations}

CAT: COPD Assessment Test; CCQ: Clinical COPD Questionnaire;

$\mathrm{Cl}$ : Confidence Interval; COPD: Chronic Obstructive Pulmonary Disease; CRQ: Chronic Respiratory Questionnaire; FEV1\%Pred: Forced Expiratory Volume in $1 \mathrm{~s} \%$ predicted; GOLD: Global initiative for Obstructive Lung Diseases; GRC: Global Rating of Change scale; HRQoL: Health-Related Quality of Life; ICC: Intraclass Correlation Coefficient; MCID: Minimal Clinically Important Difference; N: Number of patients; PR: Pulmonary Rehabilitation; PRO: Patient-Reported Outcome; RIMTCORE: Routine Inspiratory Muscle Training within COPD Rehabilitation; SD: Standard Deviation; SF-36: ShortForm 36; SGRQ: St. George's Respiratory Questionnaire; TO: Pre-rehabilitation measurement; T1: Post-rehabilitation measurement; T2: Time-point 2: 3 month follow-up; T3: Time-point 3: 6 month follow-up; T4: Time-point 4: 9 month follow-up; T5: Time-point 5: 12 month follow-up

\section{Acknowledgements}

We are grateful to the Junior Scientific Masterclass of the University of Groningen, who financially supported the research position of the first author.

\section{Funding}

The main RIMTCORE trial (\#DRKS00004609) concerning the effects of IMT training during pulmonary rehabilitation was funded by the Deutsche Rentenversicherung (German Pension Insurance South Bavaria). The current study regarding the $M C I D$ of the $C C Q, C A T$ and $S G R Q$ received financial support from the Junior Scientific Masterclass as part of the University of Groningen.

\section{Availability of data and materials}

The data that support the findings of this study are not publicly available. Participating patients have only agreed upon availability of their data to the Klinik Bad Reichenhall, their scientific partners in the data analysis and the Committee of the Bavarian State Chamber of Labor in Munich.

\section{Authors' contributions}

KS, MW, DJ and MS planned the RIMTCORE study design regarding the effects of IMT training during pulmonary rehabilitation, and were responsible for data collection. HA, CdJ, RS and TvdM designed the current study regarding the MCID of the CCQ, CAT and SGRQ. HA, CdJ and BK performed the statistical analysis. HA wrote the first draft, while CdJ, BK, JK, RS and TvdM actively participated in the review process. RS and TvdM supervised and participated in different steps of the study, as well as in writing. All authors participated in various steps in the study, edited the manuscript and gave their approval for submission.

\section{Ethics approval and consent to participate}

This study is a secondary analysis of a subsample from the Routine Inspiratory Muscle Training within COPD Rehabilitation (RIMTCORE) real-life randomized controlled trial (\#DRKS00004609) in the Klinik Bad Reichenhall, Center for Rehabilitation, Pulmonology and Orthopaedics in Germany. All patients signed informed consent upon participation. The RIMTCORE trial was approved by the Ethik-Kommission der Bayerischen Landesärztekammer (\#12107) and registered in the German Clinical Trial Register.

\section{Consent of publication}

All authors participated in various steps in the study, edited the manuscript and gave their approval for submission.

\section{Competing interests}

H.J. Alma, C. de Jong, D. Jelusic, M. Wittmann, M. Schuler, B.J. Kollen and R. Sanderman have nothing to disclose. J.W.H. Kocks reports personal fees from Novartis; research grants and personal fees from Boehringer Ingelheim; research grants and personal fees from GSK; research grants from Stichting Zorgdraad; personal fees from IPCRG; personal fees from Springer Media; and trave arrangements from Chiesi BV, GlaxoSmithKline BV, and IPCRG, all outside the submitted work. K. Schultz received lecture fees from Boehringer, AstraZeneca, Berlin Chemie, Novartis, Chiesi, Mundipharma, Takeda, GSK and MSD, all outside the submitted work. T. van der Molen reports personal reimbursements from GSK, TEVA, Astra Zeneca, Boehringer Ingelheim and study grants from Astra Zeneca and GSK. After this study was terminated, he became employee of GSK. None of these stated conflicts of interest are linked to the current manuscript. T. van der Molen developed the CCQ and holds the copyright.

\section{Publisher's Note}

Springer Nature remains neutral with regard to jurisdictional claims in published maps and institutional affiliations.

\section{Author details}

${ }^{1}$ University of Groningen, University Medical Center Groningen, Department of General Practice and Elderly Care Medicine, HPC FA21, Postbox 196, NL-9700, AD, Groningen, The Netherlands. 'University of Groningen, University Medical Center Groningen, Groningen Research Institute for Asthma and COPD (GRIAC), Groningen, The Netherlands. ${ }^{3}$ Klinik Bad Reichenhall, Center for Rehabilitation, Pulmonology and Orthopedics, Bad Reichenhall, Germany. ${ }^{4}$ University of Wuerzburg, Department of Medical Psychology and Psychotherapy, Medical Sociology and Rehabilitation Sciences, Wuerzburg, Germany. ${ }^{5}$ University of Groningen, University Medical Center Groningen, Department of Health Psychology, Groningen, The Netherlands. EUniversity of Twente, Department of Psychology, Health and Technology, Enschede, The Netherlands.

Received: 16 November 2017 Accepted: 30 May 2018

Published online: 26 June 2018

\section{References}

1. Reardon JZ, Lareau SC, Zu Wallack R. Functional status and quality of life in chronic obstructive pulmonary disease. Am J Med. 2006;119(10 Suppl 1):32-7.

2. Jones PW. Health status measurement in chronic obstructive pulmonary disease. Thorax. 2001;56(11):880-7.

3. Jones PWHS. What does it mean for payers and patients? Proc Am Thorac Soc. 2006;3:222-6. 
4. Guyatt GH, Feeny DH, Patrick DL. Measuring health-related quality of life. Ann Intern Med. 1993;118:622-9.

5. Jaeschke R, Singer J, Guyatt GH. Measurement of health status. Ascertaining the minimal clinically important difference Control Clin Trials. 1989;10:407-15.

6. Copay AG, Subach BR, Glassman SD, Polly DW Jr, Schuler TC. Understanding the minimum clinically important difference: a review of concepts and methods. Spine J. 2007;7:541-6.

7. Revicki D, Hays RD, Cella D, Sloan J. Recommended methods for determining responsiveness and minimally important differences for patient-reported outcomes. J Clin Epidemiol. 2008;61:102-9.

8. Beaton DE, Boers M, Wells GA. Many faces of the minimal clinically important difference (MCID): a literature review and directions for future research. Curr Opin Rheumatol. 2002;14:109-14.

9. Kamper SJ, Maher CG, Mackay G. Global rating of change scales: a review of strengths and weaknesses and considerations for design. J Man Manip Ther. 2009;17:163-70

10. Grøvle L, Haugen AJ, Hasvik E, Natvig B, Brox Jl, Grotle M. Patients' ratings of global perceived change during 2 years were strongly influenced by the current health status. J Clin Epidemiol. 2014;67:508-15.

11. Crosby RD, Kolotkin RL, Williams GR. Defining clinically meaningful change in health-related quality of life. J Clin Epidemiol. 2003;56:395-401.

12. Jones PW, Price D, Van der Molen T. Role of clinical questionnaires in optimizing everyday care of chronic obstructive pulmonary disease. Int J Chron Obstruct Pulmon Dis. 2011;6:289-96.

13. Curtis JR, Patrick DL. The assessment of health status among patients with COPD. Eur Respir J Suppl. 2003;41:36s-45s.

14. Tsiligianni I, Kocks J, Tzanakis N, Siafakas N, Van der Molen T. Factors that influence disease-specific quality of life or health status in patients with COPD: a review and meta-analysis of Pearson correlations. Prim Care Respir J. 2011;20(3):257-68.

15. Westwood, M., Bourbeau, J., Jones, P.W., Cerulli, A., Capkun-Niggli, G., Worthy G. Relationship between FEV1 change and patient-reported outcomes in randomised trials of inhaled bronchodilators for stable COPD: a systematic review. Respir Res 2011, 12: 40-9921-12-40.

16. Jones PW, Harding G, Berry P, Wiklund I, Chen WH, Kline Leidy N. Development and first validation of the COPD assessment test. Eur Respir J. 2009;34:648-54.

17. Van der Molen T, Willemse BW, Schokker S, ten Hacken NH, Postma DS, Juniper EFD. Validity and responsiveness of the clinical COPD questionnaire. Health Qual Life Outcomes. 2003;1:13.

18. Jones PW, Quirk FH, Baveystock CM. The St George's respiratory questionnaire. Respir Med. 1991;85:25-31.

19. Global Initiative for Chronic Obstructive Lung Disease (GOLD). Global Strategy for the Diagnosis, Management and Prevention of COPD (2017 Report). 2017; Available at http://www.goldcopd.org/gold-2017-global-strategy-diagnosismanagement-prevention-copd/. Accessed 11th of July 2017.

20. Kocks JWH, Blom CMG, Kasteleyn MJ, Oosterom W, Kollen BJ, Van der Molen T, Chavannes NH. Feasibility and applicability of the paper and electronic COPD assessment test (CAT) and the clinical COPD questionnaire (CCQ) in primary care: a clinimetric study. Npj Primary Care Respiratory Medicine. 2017;27(1):20.

21. Kocks JW, Tuinenga MG, Uil SM, van den Berg JW, Ståhl E, der Molen V. T. Health status measurement in COPD: the minimal clinically important difference of the clinical COPD questionnaire. Respir Res. 2006;7:62.

22. Kon SS, Dilaver D, Mittal M, Nolan CM, Clark AL, Canavan JL, Jones SE, Polkey MI, Man WD. The clinical COPD questionnaire: response to pulmonary rehabilitation and minimal clinically important difference. Thorax. 2013;69:793-8

23. Canavan JL, Dilaver D, Clark AL, Jones SE, Nolan CM, Kon SS, Man WD. Clinical COPD questionnaire in patients with chronic respiratory disease. Respirology. 2014;19:1006-12

24. Tsiligianni IG, van der Molen T, Moraitaki D, Lopez I, Kocks JW, Karagiannis K, Siafakas N, Tzanakis N. Assessing health status in COPD. A head-to-head comparison between the COPD assessment test (CAT) and the clinical COPD questionnaire (CCQ). BMC Pulm Med. 2012;12:20.

25. Alma H, de Jong $C$, Jelusic D, Wittmann M, Schuler M, Flokstra-de Blok B, Kocks J, Schultz K, Van der Molen T. Health status instruments for patients with COPD in pulmonary rehabilitation: defining a minimal clinically important difference. Npj PCRM. 2016;26:16041.

26. Smid DE, Franssen FM, Houben-Wilke $S$, Vanfleteren LE, Janssen DJ, Wouters EF, Spruit MA. Responsiveness and MCID estimates for CAT, CCQ and HADS in patients with COPD undergoing pulmonary rehabilitation: a prospective analysis. J Am Med Dir Assoc. 2017;18(1):53-8.

27. Kon SS, Canavan JL, Jones SE, Nolan CM, Clark AL, Dickson MJ, Haselden BM, Polkey MI, Man WD. Minimum clinically important difference for the COPD assessment test: a prospective analysis. Lancet Respir Med. 2014;2:195-203.

28. Dodd JW, Hogg L, Nolan J, Jefford H, Grant A, Lord VM, Falzon C, Garrod R, Lee C, Polkey Ml, Jones PW, Man WD, Hopkinson NS. The COPD assessment test (CAT): response to pulmonary rehabilitation. A multicentre, prospective study. Thorax. 2011;66:425-9.

29. Jones PWS. George's respiratory questionnaire: MCID. COPD. 2005;2:75-9.

30. Welling JB, Hartman JE, Ten Hacken NH, Klooster K, Slebos DJ. The minimal important difference for the St George's respiratory questionnaire in patients with severe COPD. Eur Respir J. 46:1598.

31. Jones PW, Bosh TK. Quality of life changes in COPD patients treated with salmeterol. Am J Respir Crit Care Med. 1997;155:1283-9.

32. Schultz $K$, Jelusic $D$, Wittmann $M$, Krämer B, Huber V, Fuchs S, Lehbert N, Wingart S, Stojanovic D, Göhl O, Alma HJ, de Jong C, van der Molen T, Faller $\mathrm{H}$, Schuler M. Inspiratory muscle training does not improve clinical outcomes in 3-week COPD rehabilitation: results from a randomised controlled trial. Eur Respir J 2018 Jan 25;51(1). pii: 1702000.

33. Gupta N, Pinto LM, Morogan A, Bourbeau J. The COPD assessment test: a systematic review. Eur Respir J. 2014 Oct;44(4):873-84.

34. Zhou Z, Zhou A, Zhao Y, Chen P. Evaluating the clinical COPD questionnaire: a systematic review. Respirology. 2017 Feb;22(2):251-62.

35. Ware J.E. et al. SF-36 Health Survey: Manual and Interpretation Guide. The Health Institute, New England Medical Center Boston, Massachusetts.

36. Terwee CB, Bot SD, de Boer MR, van der Windt DA, Knol DL, Dekker J, et al. Quality criteria were proposed for measurement properties of health status questionnaires. J Clin Epidemiol. 2007;60:34-42.

37. Afshartous D, Preston RA. Confidence intervals for dependent data: equating non-overlap with statistical significance. Computational Statistics and Data Analysis. 2010;54:2296-305.

38. Guyatt GH, Norman GR, Juniper EF, Griffith LE. A critical look at transition ratings. J Clin Epidemiol. 2002;55:900-8.

39. Stull DE, Kline Leidy N, Parasuraman B, Chassany O. Optimal recall periods for patient-reported outcomes: challenges and potential solutions. Curr Med Res Opin. 2009;25(4):929-42.

40. Kjellson G, Clarke P, Gerdtham UG. Forgetting to remember or remembering to forget: a study of the recall period length in health care survey questions. J Health Economics. 2014;35:34-46.

41. Schmitt JS, Abbott JH. Global ratings of change do not accurately reflect functional change over time in clinical practice. J Orthop Sports Phys Ther. 2015:45(2)

42. Schmitt JS, Abbott JH. Patient global ratings of change did not adequately reflect change over time: a clinical cohort study. Phys Ther. 2014;94:534.

43. Schmitt J, Di Fabio RP. The validity of prospective and retrospective global change criterion measures. Arch Phys Med Rehabil. 2005;86:2270-6.

44. Kamper SJ, Ostelo RW, Knol DL, Maher CG, de Vet HC, Hancock MJ. Global perceived effect scales provided reliable assessments of health transition in people with musculoskeletal disorders, but ratings are strongly influenced by current status. J Clin Epidemiol. 2010;63(7):760-6.

45. Norman GR, Stratford P, Regehr G. Methodological problems in the retrospective computation of responsiveness to change: the lesson of Cronbach. J Clin Epidemiol. 1997;50:869-79.

46. Dworkin RH, Turk DC, Wyrwich KW, et al. Interpreting the clinical importance of treatment outcomes in chronic pain trials: IMMPACT recommendations. J Pain. 2008;9:105-21.

47. Herrmann D. Reporting current, past, and changed health status. What we know about distortion. Med Care. 1995;33(4 Suppl):AS89-94.

48. Meek PM, Lareau SC, Anderson D. Memory for symptoms in COPD patients: how accurate are their reports? Eur Respir J. 2001;18:474-81.

49. Seidl H, Meisinger C, Kirchberger I, Burkhardt K, Kuch B, Holle R. Validity of self-reported hospital admissions in clinical trials depends on recall period length and individual characteristics. J Eval Clin Pract. 2016;22:446-54.

50. Shi Q, Trask PC, Wang XS, Mendoza TR, Apraku WA, Malekifar M, Cleeland CS. Does recall period have an effect on cancer patients' ratings of the severity of multiple symptoms? J Pain Symptom Manag. 2010;40:191-9.

51. Bennett AV, Amtmann D, Diehr P, Patrick DL. Comparison of 7-day recall and daily diary reports of COPD symptoms and impacts. Value Health. 2012; 15:466-74. 
52. Norquist JM, Girman C, Fehnel S, DeMuro-Mercon C, Santanello N. Choice of recall period for patient-reported outcome (PRO) measures: criteria for consideration. Qual Life Res. 2012;21:1013-20.

53. Jones, P.W., Beeh, K.M., Chapman, K.R., Decramer, M., Mahler, D.A., Wedzicha, J.A. Minimal clinically important differences in pharmacological trials. Am J Respir Crit Care Med 2014, 1; 189(3):250-255.

54. Schwartz CE, Sprangers MAG. Methodological approaches for assessing response shift in longitudinal health-related quality-of-life research. Soc Sci Med. 1999:48:1531-48.

55. Ousmen A, Conroy T, Guillemin F, Velten M, Jolly D, Mercier M, Causeret S, Cuisenier J, Graesslin O, Hamidou Z, Bonnetain F, Anota A. Impact of the occurrence of a response shift on the determination of the minimal important difference in a health-related quality of life score over time. Health Qual Life Outcomes. 2016;14:16.

56. Lacasse, Y., Goldstein, R., Lasserson, T.J., Martin, S. Pulmonary rehabilitation for chronic obstructive pulmonary disease. Cochrane Database Syst Rev. 2006, 18;(4): CD003793.

57. Phillips A, Fletcher C, Atkinson G, Channon E, Douiri A, Jaki T, Maca J, Morgan D, Roger JH, Terrill P. Multiplicity: discussion points from the statisticians in the pharmaceutical industry multiplicity expert group. Pharmaceut Statist. 2013;12:255-9.

Ready to submit your research? Choose BMC and benefit from:

- fast, convenient online submission

- thorough peer review by experienced researchers in your field

- rapid publication on acceptance

- support for research data, including large and complex data types

- gold Open Access which fosters wider collaboration and increased citations

- maximum visibility for your research: over $100 \mathrm{M}$ website views per year

At BMC, research is always in progress.

Learn more biomedcentral.com/submissions 